\title{
PENENTUAN KETIDAKPASTIAN KALIBRASI BESARAN \\ MASSA PADA TIMBANGAN ANALITIS DI LABORATORIUM \\ UJI DAN KALIBRASI BBKB
}

Isnaini!

Pudjo Yuwono ${ }^{2}$

\section{ABSTRAK}

Perangkat ukur dikatakan dalam kondisi baik jika dapat memberikan informasi yang aktual. Perangkat ukur tersebut harus menjamin hasil pengukuran sesuai dengan standar nasional maupun internasional. Kalibrasi perangkat ukur merupakan prosedur standar untuk menjaga kondisi instrument ukur dan bahan ukur agar tetap sesuai dengan spesifikasi teknis. Penelitian ini dilakukan untuk menentukan besarnya ketidakpastian (uncertainty) pada kalibrasi besaran massa khususnya pada parameter kalibrasi timbangan analitis merk Sartorius Type BL210S.Prosedur kalibrasi dilakukan dengan serangkaian penimbangan massa standar terkalibrasi untuk menentukan nilai ketidakpastian. Data hasil kalibrasi telah dianalisis dan menghasilkan nilai Expanded Uncertainty Uexp $=0,26$, faktor cakupan $\mathrm{K}=1,96$, pada tingkat kepercayaan $\mathrm{CL}=95 \%$.

Kata kunci : ketidakpastian, massa, timbangan analitis

\begin{abstract}
Measuring device is said to be in good condition if you can provide real-time information. Measuring devices must ensure the measurement results in accordance with national and international standards. Calibration of the measuring device is a standard procedure to maintain the condition of the measuring instrument and measuring the material to remain in accordance with technical specifications. This research was conducted to determine the amount of uncertainty (uncertainty) on calibration of the mass scale calibration parameters, especially on an analytical balance sartorius brands Type BL210S. Procedural calibration is done by weighing a series of mass standards calibrated to determine the value of uncertainty. Calibration results have been analyzed, and produce value $=0.26$ Uexp Expanded uncertainty, coverage factor $K=1.96$, the confidence level $C L$ is $95 \%$.
\end{abstract}

Key words: uncertainty, mass, analytical balances

'Isnaini : Balai Besar Kerajinan dan Batik Yogyakarta ${ }^{2}$ Pudjo Yuwono : Balai Besar Kerajinan dan Batik 


\section{LATAR BELAKANG}

Kalangan industri semakin sadar akan pentingnya melakukan kalibrasi berbagai peralatan produksinya. Hal ini akibat tuntutan pasar tentang perlu diting ISO 9001 yang menjamin kredibilitas mengaitkan penilaiannya dengan berbagai ISO, misarat produk ekspor agar bisa diterima di luar suatu produk. Selain itu, uji mutu sudah menjak meningkatkan mutu suatu produk salah satu yang negeri dan mampu bersaing secara global. Untuk makan baku (Noviyanti, 2005).

dapat dilakukan adalah dengan pengendalian bahan pengujian bahan tersebut sebelum digunakan

- Pengendalian bahan baku dapat dilakukan deng baik juga sangat ditentukan oleh pemantauan dalam proses produksi. Proses produksi yan ukur dan uji dapat diketahui kondisinya dengan alat ukur yang tepat dan akurat. Pera karena itu kalibrasi menjadi penting artinya apabhasil

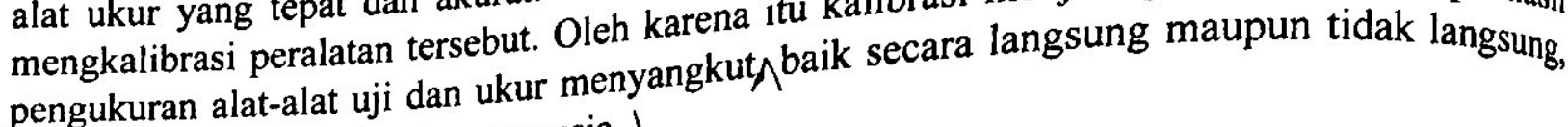
kepentingan dan keselamatan manusia. 1

- tidak diinginkan terjadinya cacat dan/atau penyimpangan hasil produksi

- untuk menjamin mutu, diperlukan bukti bahwa hasil-hasil pengukuran mempunyai keterlusuran ke standar-standar nasional dan/atau internasional (http://www.mutucertification.com/index. php?ar_id=l)

Penimbangan merupakan salah satu variabel proses yang digunakan dan harus diperhatikan dalam aplikasi di industri maupun aplikasi yang lain. Dalam proses pembatikan penimbangan resep bahan warna yang benar dapat menyeragamkan hasil yang dikehendaki. Untuk itu perlu dilakukan kalibrasi timbangan yang digunakan.

Definisi kalibrasi adalah suatu kegiatan yang membentuk hubungan antara nilai - nilai yang ditunjukkan oleh instrument pengukur atau system pengukuran, atau nilai yang diwakili oleh bahan ukur, dengan nilai- nilai yang sudah diketahui yang berkaitan dạiri besaran yang diukur dalam kondisi tertentu. Peralatan yang akan dikalibrasi perlu diidentifikasi sebelum dilakukan kalibrasi terlebih dahulu untuk mengetahui rentang ukur, penggunaan alat dan spesifikasi lain yang diperlukan. Kalibrasi timbangan dilakukan dengan meletakkan massa standar yang nilainya sudah diketahui dari kalibrasi oleh lembaga kalibrasi terakreditasi. Di Indonesia, Lembaga yang memberikan akreditasi laboratorium adalah Komite Akreditasi Nasional (Renanta Hayu, 2003). Tujuan penelitian ini akan memaparkan bagian dari kegiatan kalibrasi untuk menentukan nilai ketidakpastian pada proses kalibrasi timbangan digital analitis BL210S merk AND dengan tingkat ketelitian $0.1 \mathrm{mg}$, menggunakan batu timbang standar kelas F1 sehingga dapat diperoleh hasil
ketidakpastian penimbangan.

\section{METODOLOGI PENELITIAN}

- Peralatan yang digunakan dalam penelitian ini, meliputmasa standar (batu timbang terkalibrasi)

- timbangan analitik kapasitas $210 \mathrm{~g}$ ketelitian $0.1 \mathrm{mg}$

- pinset yang

\section{Prosedur penelitian.}

Timbangan diukur daya ulang pembacaan dan penyimpangan dari skala non buku The Calibration of Balances, DB Prowse dan evaluasi ketiskala nominal dengan metode dari 
dengan ISO GUM. Model matematis dari pengukuran yang dilakukan adalah :

$$
C i=M i-\left(r^{-} i-z^{-i}\right)
$$

keterangan :

Ci adalah koreksi yang dihitung untuk titik pengukuran ke-i

$\mathrm{Mi}$

ri

adalah massa konvensional standar massa untuk titik pengukuran ke-i

adalah rata- rata dari dua kali pembacaan berulang dengan beban untuk titik ke-i

$=i$

adalah rata- rata pembacaan tanpa beban untuk titik ke-i Daya ulang pembacaan timbangan

Pengamatan daya ulang pembacaan dilakukan dengan melakukan sepuluh kali pengukuran berulang untuk massa yang sama tanpa melakukan adjustment terhadap setting "nol" timbangan, termasuk fasilitas autozero timbangan. Simpangan baku dihitung dari perbedaan pembacaan timbangan ( $r$ ) pada saat timbangan tidak diberi beban $(z)$ dan pembacaan pada saat timbangan diberi beban $(\mathrm{m})$ sehingga $\mathrm{ri}=\mathrm{mi}-\mathrm{zi}$

a. Penyimpangan dari nilai skala nominal

Diperoleh dengan melakukan penimbangan ganda untuk setiap pengukuran dengan menggunakan satu set anak timbangan yang telah dikalibrasi. Timbangan dipersiapkan dengan menjalankan system kalibrasi internal otomatis dan menonaktifkan system autozero. Urutan pengukuran meliputi catat pembacaan nol tanpa beban. Letakkan massa di atas pan, catat pembacaan dengan beban, angkat standar massa, catat pembacaan dengan beban, letakkan lagi standar massa di atas, setelah itu angkat standar massa dari pan dan catat pembacaan timbangan saat tanpa beban. Prosedur ini dilakukan untuk serangkaian penimbangan pada interval yang sama untuk setiap $10 \%$ kapasitas timbangan.

b. Perhitungan koreksi

Penimbangan pada skala nominal $180 \mathrm{~g}$ menggunakan standar batu timbang yang paling banyak, yaitu batu timbang dengan nominal $10 \mathrm{~g}, 20 \mathrm{~g}, 50 \mathrm{~g}$, dan batu timbang nominal $100 \mathrm{~g}$. Oleh karena itu pada titik penimbangan ini akan dilakukan perhitungan koreksi dan ketidakpastian penimbangan. Massa konvensional masing - masing batu timbang sesuai yang tercantum dalam sertifikat kalibrasi dapat dilihat pada tabel 1 .

Tabel 1.Batu timbang yang digunakan pada penimbangan $180 \mathrm{~g}$

\begin{tabular}{|c|c|}
\hline $\begin{array}{c}\text { Nominal } \\
(\mathbf{g})\end{array}$ & $\begin{array}{c}\text { Massa Konvensional } \\
(\mathbf{g})\end{array}$ \\
\hline $\mathbf{1 0}$ & 10.000044 \\
\hline $\mathbf{2 0}$ & 19.999789 \\
\hline $\mathbf{5 0}$ & 50.000069 \\
\hline $\mathbf{1 0 0}$ & 100.000286 \\
\hline Total (M.) & 180.000188 \\
\hline
\end{tabular}




\section{HASIL DAN PEMBAHASAN}

\section{Hasil penelitian}

1. Hasil pengamatan penimbangan $180 \mathrm{~g}$

Dari hasil pengamatan didapat data :

Tabel 2. Hasil Pengamatan Penimbangan 180

\begin{tabular}{|l|r|}
\hline Pengamatan tanpa beban ke - & 0.0000 \\
\hline Pengamatan dengan beban ke - & 180.0664 \\
\hline Pengamatan dengan beban ke -2 & 180.0663 \\
\hline Pengamatan tanpa beban ke -2 & 0.0000 \\
\hline
\end{tabular}

Rata rata perbedaan pengamatan tanpa beban dan dengan beban adalah 180.06635 sehingga koreksi pada titik skala nominal $180 \mathrm{~g}$ adalah $(180.000188-180.06635)=-0.066162 \mathrm{mg}$

\section{Perhitungan ketidakpastian}

Tahap lanjut dari proses kalibrasi massa adalah penghitungan ketidakpastian.

a. Ketidakpastian baku standar massa

Penimbangan pada nominal $180 \mathrm{~g}$ menggunakan 4 buah anak timbang standar yaitu $100 \mathrm{~g}, 50 \mathrm{~g}$, $20 \mathrm{~g}$, dan $10 \mathrm{~g}$. Data yang relevan dari 4 buah anak timbang standar didapatkan dari sertifikat kalibrasi yang dikeluarkan oleh lembaga kalibrasi eksternal. Ketidakpastian kalibrasi dinyatakan dalam tingkat kepercayaan $95 \%$.

Tabel 3. Ketidakpastian Baku Standar Massa

\begin{tabular}{|c|r|r|c|}
\hline $\begin{array}{c}\text { Nominal } \\
(\mathbf{g})\end{array}$ & $\begin{array}{c}\text { Massa Konvensional } \\
(\mathbf{g})\end{array}$ & $\begin{array}{c}\text { Ketidakpastian } \\
(\mathbf{m g})\end{array}$ & Nilai $\mathbf{K}$ \\
\hline 10 & 10,000044 & 0,031 & 2 \\
\hline $20^{*}$ & 19,999789 & 0,036 & 2 \\
\hline 50 & 50,000069 & 0,041 & 2 \\
\hline 100 & 100,000286 & 0,061 & 2 \\
\hline
\end{tabular}

Nilai ketidakpastian $U$, diperoleh dengan rumus

$$
U 1=\frac{\sqrt{0,031^{2}+0,036^{2}+0,041^{2}+0,061^{2}}}{2}
$$

Yang menghasilkan nilai $U_{1}=0,04376$

b. Ketidakpastian baku daya ulang pembacaan

Daya ulang pembacaan timbangan sebelumnya telah dihitung dan menghasilkan nilai standar $S D / \sqrt{n}$. Maka ketidakpastiannya, $u 2=\frac{0.000057}{\sqrt{10}}=0,00002 \mathrm{mg}$ dengan derajat kebebasannya di ambil
dari jumlah pengamatan yang digunakan untuk menghitung standar deviasi timbanan, yaitu=n
$l=9$ 


\section{c. Ketidakpastian baku resolusi timbangan}

Resolusi timbangan untuk rentang ukur rendah adalah $0.1 \mathrm{mg}$. Dengan mengasumsikaan skala dibulatkan ke nilai terdekat $0.1 \mathrm{mg}$ maka terdapat kesalahan pembulatan sebesar $0.05 \mathrm{mg}$ diberikan dengan distribusi rectangular, schingga ketidakpastian bakunya adalah:

$$
\mathrm{u} 3=0.05 /(3)^{\wedge} 0.5=0,02887 \mathrm{mg}
$$

nilai tak hingea.

$$
v=1.00 \mathrm{e}+6
$$

Pengaruh buoyancy udara terhadap pembacaan timbangan diasumsikan mempunyai semi-range bakunya adalah:

e. Ketidakpastian baku gabungan :

$$
\begin{aligned}
& u 4=1000 \times\left(10^{-6} \times 180 \mathrm{~g}\right) /\left(3^{1 / 2}\right)=0,104 \mathrm{mg} \\
& \text { abungan : }
\end{aligned}
$$

f. Ketidakpastian bentangan :

$$
u c=\left\{u 1^{2}+u 2^{2}+u 3^{2}+u 4^{2}\right\}^{1 / 2}=0,1163962
$$

\begin{tabular}{|c|c|c|c|c|c|c|c|c|c|c|}
\hline Component & Units & Dist. & $U$ & Divisor & 1 & $u i$ & $\mathrm{Ci}$ & $u i C i$ & $\begin{array}{c}\left(\begin{array}{c}u i C i) \\
12\end{array}\right. \\
\end{array}$ & $\begin{array}{c}(u i C i)^{k} \\
4 / u i\end{array}$ \\
\hline $\begin{array}{l}\text { Daya } \\
\text { pengulangan }\end{array}$ & $\mathrm{mg}$ & Normal & $\begin{array}{c}5,68 \mathrm{E}- \\
05 \\
\end{array}$ & 3,16 & 9 & 0,00002 & 1 & 0,00002 & 0,0000000 & $\begin{array}{c}1,15364 \mathrm{E}- \\
20\end{array}$ \\
\hline $\begin{array}{l}\text { Resolusi } \\
\text { UUT } \\
\end{array}$ & $\mathrm{mg}$ & Rect. & 0,05 & 1,73 & $1,00 \mathrm{E}+06$ & 0,02887 & 1 & 0,02887 & 0,0008333 & $\begin{array}{c}6,94444 \mathrm{E}- \\
13 \\
\end{array}$ \\
\hline $\begin{array}{l}\text { Standard } \\
\text { massa }\end{array}$ & $\mathrm{mg}$ & Normal & 0,0875 & 2,00 & 60 & 0,04376 & 1 & 0,04376 & 0,0019148 & $\begin{array}{c}6,11045 E- \\
08\end{array}$ \\
\hline \multirow[t]{6}{*}{ Buoyancy } & $\mathrm{mg}$ & Rect. & 0,18 & 1,73 & $1,00 \mathrm{E}+06$ & 0,10392 & 1 & 0,10392 & 0,0108000 & $\begin{array}{c}1,1664 \mathrm{E}- \\
10\end{array}$ \\
\hline & & & & Sums & & & & & 0,0135481 & $\begin{array}{c}6,12218 E- \\
08\end{array}$ \\
\hline & & & & \multicolumn{4}{|c|}{ Combined Standard uncertainty, uc, } & $m g$ & \multicolumn{2}{|c|}{0,1163962} \\
\hline & & & & \multicolumn{3}{|c|}{ Derajat kebebasan effektif } & & & \multicolumn{2}{|c|}{2998,125} \\
\hline & & & & \multicolumn{5}{|c|}{ Coverage factor, $k$ for Veff \& CL $95 \%$} & \multicolumn{2}{|c|}{1,96} \\
\hline & & & & \multicolumn{3}{|c|}{ Expnded uncertainty, $U=k u c$, } & & $m g$ & \multicolumn{2}{|c|}{0,23} \\
\hline
\end{tabular}

Dari perhitungan derajat kebebasan efektif diperoleh nilai derajat kebebasan 2998,125, sehingga dapat digunakan faktor cakupan $\mathrm{k}=1,96$,

$$
\mathrm{U}=1,96 \times 0,1163962 \mathrm{mg}=0.23 \mathrm{mg}
$$

Tabel 4. Kontribusi Ketidakpastian 


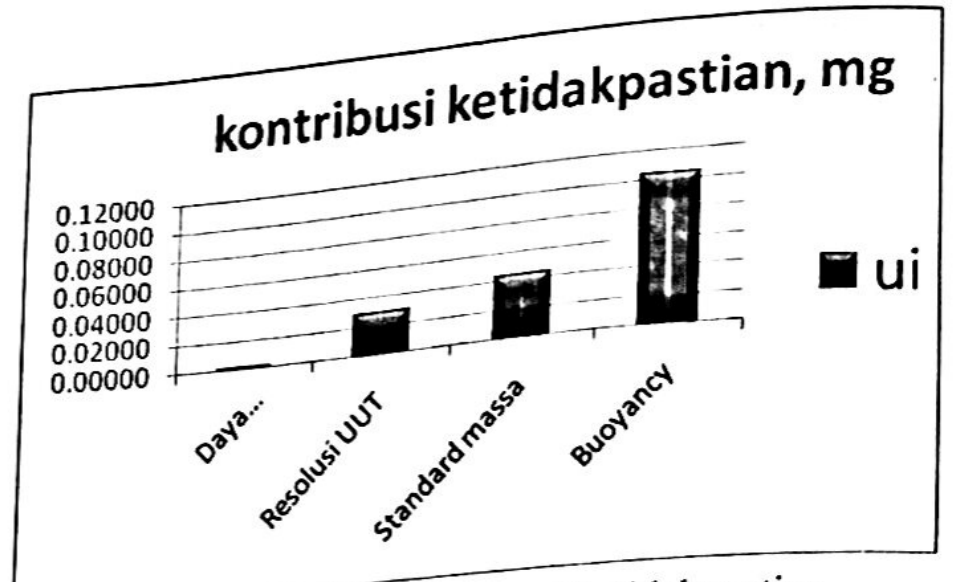

Gambar 1. Grafik kontribusi ketidakpastian

KESIMPULAN
Hasil kalibrasi timbangan elektronik pada nilai skala nominal $180 \mathrm{~g}$ mempunyai koreksi -0.066162 mg dengan ketidakpastian $\pm 0,23 \mathrm{mg}$

DAFTAR PUSTAKA
Hayu, Renanta, Teknik Pengukuran \& Analisis Data Kalibrasi Timbangan Elektronik, materi diklą, Yogyakarta, 2003

Http://www.mutucertification.com/index.php?ar_id=1, didownload pada maret 2010

Isnaini, Perhitungan BMC kalibrasi timbangan analitis di Laboratorium Kalibrasi BBKB, Yogyakarta, 2010

KAN, Suplemen Pedoman evaluasi dan pelaporan ketidakpastian pengukuran, Jakarta, 2002

Noviyanti, Analisis pengawasan mutu dalam usaha meningkatkan mutu produk pada PT Anugrah Plastindo Lestari, Universitas Bina Nusantara, 2005

Permana, W, Perhitungan statistik untuk penentuan ketidakpastian pengukuran dan evaluasi BMC: Materi diklat, Serpong, 2007

Prowse, DB, The Calibration of Balances", CSIRO, Australia, 1985 